\title{
Tradisi Khabanti Kantola sebagai Model Pendidikan Karakter Terintegrasi Kurikulum Lokal dalam Pendidikan Seni Budaya di Sekolah Menengah Kabupaten Muna.
}

\author{
LA TAENA, ${ }^{1}$ LA ODE ALI BASRI, ${ }^{2}$ LA ODE BALAWA, ${ }^{3}$ RASIAH ${ }^{4}$ \\ 1. Jurusan Pendidikan dan Ilmu Pengetahuan Sosial, Fakultas Keguruan dan Ilmu Pendidikan, \\ Universitas Halu Oleo Kendari, Indonesia, \\ 2. Jurusan Ilmu Sejarah, Fakultas Ilmu Budaya, Universitas Halu Oleo Kendari, Indonesia, \\ 3.Jurusan Pendidikan Bahasa dan Seni, Fakultas Keguruan dan Ilmu Pendidikan, \\ Universitas Halu Oleo Kendari, Indonesia. \\ 4.Jurusan Ilmu Sastra Indonesia, Fakultas Ilmu Budaya, Universitas Halu Oleo Kendari, Indonesia. \\ E-mail: lataena60@yahoo.co.id
}

Penelitian ini bertujuan untuk mengungkapkan peran tradisi kabhanti kantola dalam pendidikan karakter yang dapat dimanfaatkan secara terintegrasi dalam mata pelajaran seni budaya (lokal) di sekolah menengah di Kabupaten Muna. Kabhanti kantola merupakan sebuah tradisi yang berfungsi sebagai sarana komunikasi dan hiburan dalam masyarakat Muna dengan pola nyanyian berbalas pantun (folksong) yang diwariskan secara turun-temurun. Lokasi penelitian adalah tiga kecamatan di kabupaten Muna yaitu, Kecamatan Katobu, Kecamatan Watuputih, dan Kecamatan Tongkuno. Data dikumpulkan melalui teknik observasi pementasan, teknik rekam, transkripsi, terjemahan, dan interpretasi, data kemudian dianalisis secara qualitatif-interpretatif. Hasil penelitian menunjukkan bahwa makna dan nilai yang muncul dalam teks-teks Kabhanti kantola mengandung berbagai ajaran, nasehat, dan kritik-kritik yang membangun, membimbing, dan mengarahkan karakter masyarakat pendukungnya Nilai-nilai itu diantaranya adalah menumbuhkan rasa kebersamaan, ajaran mengenai etika dalam pergaulan, bakti kepada orang tua, pentingnya kemapanan ekonomi sebelum berkeluarga, dan larangan terhadap judi. Kritik, arahan, dan pesan seperti ini dimaksudkan untuk menciptakan keserasian, keselarasan, dan keseimbangan sosial dalam kehidupan bermasyarakat, serta mempertahankan nilai-nilai moralitas yang diyakini benar oleh masyarakat Muna. Pendidikan karakter terintegrasi dalam pendidikan seni budaya yang berbasis budaya lokal sangat penting diterapkan di sekolah Menengah di Kabupaten Muna.

\section{Khabanti Kantola Tradition as a Character Education Model Integrated with Local Curriculum in Art and Culture Education of High Schools at Muna Regency}

This research aims at the revealing of of kabbhanti kantola tradition rol e in character education that can be utilized integratedly in cultural art lesson (the local lesson) at high schools at Muna Regency. Kabbhanti kantola is a tradition that has a function as a media of communication and consolation in Muna society with the song pattern of mutual traditional poetry (folksong) that bequeathed from generation to generation. The location of this research are three sub-districts at Muna Regency, namely Katobu sub-district, Watuputih sub-district, and Tongkuno sub-district. The data were collected through staging observation technique, recording technique, transcription, translation, and interpretation. The data then were analyzed qualitatively-interpretatively. The result of the research shows that the meaning and value that appear in the texts of kabbhanti kantola provides the varieties of precept, advice, and constructive criticism, guidance, and the building of society character who support them. Among of those values are to grow togetherness sense, precept about ethics in social intercourse, loyalty to the parents, the importance of economical ability before being married, and prohibition of gambling. Such criticism, precept, and message are aimed to create the harmony, and libration in the social life, and maintaining the morality values that Muna society trust. The character education that integrated in cultural art education in the local culture is very important to be applied at high schools at Muna Regency.

Keywords: Meaning, value, kabbhanti kantola, character education 
Kabhanti dalam ilmu folklore dapat dikategorikan sebagai jenis folksong, yaitu nyanyian rakyat berupa pantun berbalasan dengan berbagai varian atau tipe khas dari masing-masing daerah atau suku bangsa. Belakangan ini penggalian kembali tradisi-tradisi seni lokal termasuk folksong ini sedang marak dilakukan di berbagai negara termasuk di negaranegara maju seperti Amerika dan Eropa. Di Amerika, misalnya, Shane Bernard and Julia Girouard (1992) meneliti tentang "Colinda": Mysterious Origins of a Cajun Folksong. Colinda merupakan salah satu tradisi musik dan tari suku Cajun di South Louisiana Amerika Serikat, yang sekarang ini banyak menginspirasi para musisi untuk mengadaptasi dalam berbagai jenis musik, seperti pop, beat, dan Rock $n$ Roll. Penelitian ini menemukan bahwa asal mula tradisi folksong Colinda dibawa oleh orang Guinea pada abad akhir abad tujuh belas ke Amerika dan berbaur dengan beberapa tari dari Carribean dan Lousiana. Colinda kemudian diadaptasi dan menampilkan dua ciri khas yang berkaitan dengan to "Michie Proval" dan "MichieBaziro." Colinda pada intinya mengekspresikan tentang ketidaksenangan kepada figur-figur penguasa. "Michie Preval" and "MichieBaziro" biasanya mengandung sindiran bagi kelas-kelas penguasa. Di Inggris, Reichenbach (1983) mengkaji "The Tonality of English and Gaelic Folksong", sama juga dilakukan oleh generasi African American di Amerika yang mulai menggali identitas lokalnya melalui Negro folksong (Darius, 1960) dan melalui permainan musik Banjo (Conway, 2003). Conway (2003) mengatakan bahwa revitalisasi musik Banjo yang menjadi ciri khas African American sekarang ini marak dilakukan dalam programprogram hiburan di Amerika, misalnya di Apalachian, melalui program-program radio, dan televisi. Penggalian kembali musik Banjo ini dimaksudkan untuk menguatkan identitas Afrika-Amerikayang selalu identik dengan citra inferior di Amerika. Di Timur Tengah, Stephen Blum (1974). Meneliti tentang Persian Folksong In Meshhed (Iran). meninjau genre folksong dalam bahasa Persia, yang sekarang ini dikembangkan di Khorasan (provinsi terbesar di Selatan Iran). Fokus pembicaraanya adalah "The repertoire of Persian folksong" menampilkan satu komunitas yang umumnya menghasilkan sejumlah genre, beberapa membawa asosiasi wilayah tertentu, yang dapat dikenali melalui penyanyi maupun pendengarnya.Dinegara Malaisia Kajian ole Hashim, at al, (2012).
Bahwa Pantun mencerminkan budi pekerti yang mulia, budi bahasa yang santun dan akal budi yang tinggi, hal ini mencerminkan pantun sangat berkaitan dengan pendidikan karakter, ini seperti dapat dilihat dalam pantun pantun. Demikian pula hasil Penelitian yang dilakukan di Daerah Melayu oleh Fatimah Abdullah, (2009) menyatakan Pantun sangan penting dalam masyarakat Melayu an merupakan artifaks yang merakam berbagai kehidupan social, menyangkut nilai, Norma, Falsafah serta bentuk struktur dan isi kandungan melayu. Daerah Minangkabau, Kajian yang dilakukan Novita Wulasari,at al (2013). Menyatakan Pantun sangat penting. Hasil analisisnya bahwa pantun ditemukan ada nilai nilai Pendidikan karakter seperti, relegius, jujur, toleransi , disiplin, tanggung jawab, mandiri , dan rasa ingin tahu.

Di Daerah Kabupaten Muna Kajian tentang Kabhanti kantola telah dilakukan oleh beberapa peneliti, dengan tema kajian yang berbeda-beda. Dari sejumlah penelitian mengenai Kabhanti kantola, masih sedikit mengintegrasikan nilai-nilai dalam tradisi Kabhanti kantola dengan pendidikan karakter. Penelitian yang ada berhasil dihimpun adalah Ader Laepe, at al, (2006). Yang mengangkat persoalan Analisis Semiotik Atas Lirik Kantola yang difokuskan pada prilaku budaya secara kolektif oleh suku Muna di Sulawesi Tenggara dengan objeknya Kantola, serta Sitti Abadi (2012) menelaah Kabhanti kantola melalui analisis wacana kritis Kabhanti kantolaWuna, dan Darwan Sari (2011) melihat perlunya revitalisasi Kabhanti kantolakantola di era hegemoni global, serta Laode Padui (2011) menemukan dua belas nilai yang muncul dalam teks-teks Kabhanti kantolakantola, serta La Ode Sidu, M, at al, (2011). Membahas masalah Kantola dalam konteks budaya Muna. tulisan yang terakhir ini sepertinya mengungkap ciri khas kantola wuna yang membedakannya dengan tradisi-tradisi folksong serupa dalam konteks budaya lainnya.

Kabhanti kantola merupakan salah satu seni tradisi lisan dalam masyarakat Muna yang tertua dan terancam punah. Tradisi ini merupakan salah satu bentuk kesenian rakyat yang diwariskan dari generasi ke generasi. Kabhanti termasuk karya yang banyak jumlahnya yang meliputi: Kabhanti kantola, Kabhanti gambusu, dan Kabhanti modero. Meskipun menurut La Niampe (1998). Kabhanti ini 
populer di kalangan masyarakat pada zamannya dan penyebarannya sudah berlangsung lama yang meliputi seluruh daerah; Muna, Buton, Tiworo, Kulisusu, dan Kaledupa, yang berhampar di jazirah Sulawesi Tenggara. Namun kenyataannya, warisan tradisi tersebut terdengar awam di telinga generasi muda masa kini, dan serta pemanfaatan nilai-nilai dari tradisi masih kurang dielaborasi sampai pada ranah praktis yang berdaya guna di masyarakat, salah satunya dalam pengintegrasian nilai-nilai dalam tradisi dalam ranah pendidikan formal di sekolah menegah pertama.

Penelitian ini menfokuskan perhatian pada aspek peran kabhanti kantola dalam pendidikan karakter yang terintegrasi dalam pendidikan seni budaya pada kurikulum sekolah menengah di kabupaten Muna. Hal ini dipandang penting mengingat dua hal yang berkaitan dengan traadisi yang hampir hilang serta penguatan pendidikan karakter yang sudah ada melalui kearifan lokal. Fenomena yang ditampilkan oleh prilaku masyarakat terutama generasi muda sekarang ini terkadang dipandang telah melampaui nilai-nilai kehidupan yang berkaitan dengan norma, etika, moral, serta konvensi-konvensi sosial kemasyarakat.Persepsi bahwa ukuran keberhasilan tak melulu dilihat dari prestasi angka angka, tetapi juga karakter yang dapat mencerminkan kearifan, etika, dan moralitas yang penting bagi kehidupan anak di masa yang akan datang. Hendaknya institusi sekolah menjadi tempat yang senantiasa menciptakan pengalaman-pengalaman bagi siswa untuk membangun dan membentuk karakter unggul dengan beragam cara, salah satunya dengan menggali kearifan lokal masyarakat setempat.

Penelitian ini dilakukan di tiga kecamatan di kabupaten Muna; kecamatan Katobu (Raha), Kecamatan Tongkuno (WaAle-Ale), dan kecamatan Watuputih (Watuputih). Data dalam penelitian ini dikumpulkan melalui: (1) Teknik Performan lapangan: yaitu proses pengambilan data melalui pementasan Kabhanti kantola; (2) Teknik rekam; yaitu proses pengambilan data lirik-lirik dari informan yang dengan menggunakan alat rekam; (3) Teknik catat; yaitu proses pencatatan lirik-lirik Kabhanti kantola, dan informasi lain yang dianggap penting di luar data rekaman untuk menjaring informasi tambahan; (4) Teknik transkripsi; yaitu mengalihkan data dari bahasa lisan menjadi bahasa tertulis (teks); (5) Teknik terjemahan; yaitu mengalihbahasakan data
Kabhanti kantola yang berbahasa Muna ke dalam bahasa Indonesia; (6)Teknik interpretasi; yaitu menginterpretasi bahasa Kabhanti kantola untuk menemukan kandungan nilai dan makna teks secara ekplisitmanupun implisit dengan menggunakan kajian semiotik sastra.

\section{HASIL PENELITIAN}

\section{PerformanTradisi Kabhanti Kantola}

Kabhanti Kantola adalah sejenis permainan tradisional dimana para pemain berdiri berhadapan antara pemain pria dan wanita. Mereka berbalas pantun dengan irama lagu ruuruunte atau ruuruuntete. Irama ruuruunte ini menggunakan paling tinggi lima nada. Acara kantola ini biasanya dilaksanakan pada malam hari di musim kemarau saat acara panen, syukuran, dan pada acara adat lainnya. Bentuk syair Kabhanti kantola sebagian tergolong dalam prosa liris karena mementingkan irama, dan sebagiaan lagi dapat digolongkan ke dalam bentuk pantun yang di sebut talibun karena lebih dari empat baris dan jumlahnya genap. La Mokui (1991) menyatakan bahwa fungsi dan peranan Kabhanti sangat penting bagi masyarakat Muna. Kabhanti merupakan salah satu media ekspresi dalam kultur masyarakat Muna. Seseorang dapat mengekspresikan apa yang dihayalkan, dipikirkan, atau yang dikehendakinya akan disampaikan secara sastrawi melalui Kabhanti, sehingga Kabhanti menjadi salah satu media komunikasi dan hiburan bagi masyarakat Muna. Berikut beberapa sketsa pergelaran kabhanti kantola berdasarkan hasil penelitian di tiga kecamatan di kabupaten Muna.

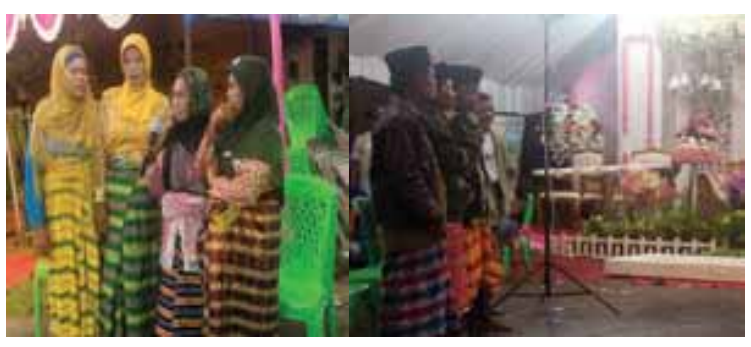

Gambar 1. Performan Kabhanti kantola di Kecamatan Katobu (Raha, 7 Juni, 2015). 


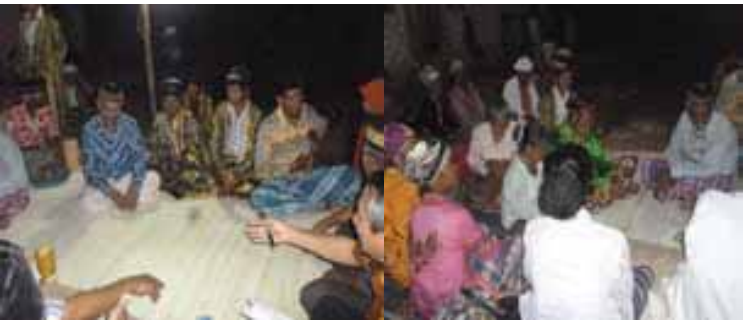

Gambar 2. Performan Kabhanti kantolaKantola di kecTongkuno (WaAle-Ale, 15 Juni 2015)

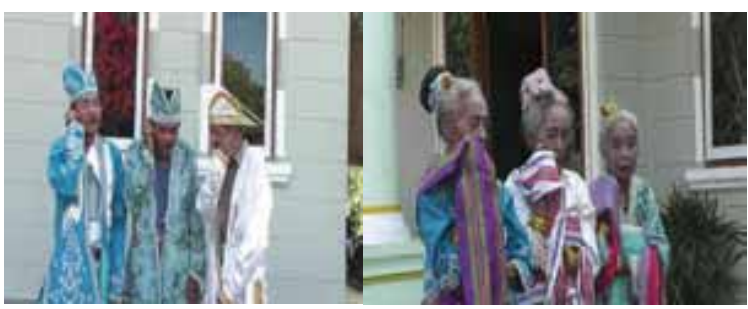

Gambar 3. Performan Kabhanti kantola Kantola di Kecamatan Watuputih (Watuputih, 20 Agustus 2015)

Dalam praktiknya, tradisi Kabhanti kantola dipertunjukkan oleh dua kelompok penyanyi; laki-laki dan perempuan. jumlah anggota dalam kelompok tidak terbatas tergantung pada kesepakatan bersama. Beberapa pertimbangan yang harus diperhatikan adalah; (1) identitas setiap anggota harus jelas, (2) pakaian setiap anggota harus seragam (pakaian adat), (3) status anggota jelas, (4) identitas pekerjaan jelas, (5) karateristik setiap anggota juga harus jelas. Kejelasan anggota ini penting untuk dipertimbangkan dengan maksud agar para peserta mudah menembak sasaran kepada siapa lagu itu ditujukan. Namun, khusus untuk pakaian yang dikenakan dalam perhelatan-jika pada dekade dahulu menggunakan pakaian adat Muna lengkap baik dari kelompok laki-laki dan perempuan, maka pada perhelatan kali ini sudah ada unsur akulturasi budaya, pakaian Muna dipadukan dengan baju kebaya modern-dan Jas/jacket sebagai simbol pakaian nasional, dan jilbab dan songko-sebagai simbol pakaian muslim, dan sarung Muna mbia-bia sebagai simbol identitas pakaian orang Muna. Rupanya hibridisasi budaya tidak terelakan dalam kehidupan masyarakat Muna, termasuk dalam momen penting pertujukkan tradisi lokal.

Tempat pelaksanaan kantola biasanya dilaksanakan dilapangan bebas. Pertimbangan strategis, aman, dan nyaman tetap menjadi prioritas utama. Jarak antara kelompok laki-laki dan perempuan tidak terlalu jauh. Sasaran kantola tergantung pada selera tim atau kelompok. Bila sasaran pantun itu ditujukan pada kelompok wanita, apakah pantunnya ditujukan pada sang janda, sang gadis, yang bersuami, yang sedang dimabuk asmara, atau kepada sang pencemburu. Bila sasaran pantun itu ditujukan kepada kelompok pria, apakah sasaran pantunnya kepada laki-laki yang mata keranjang, laki-laki banyak istri, sedang gila-gilaan dengan wanita lain. Boleh juga sasaran itu kepada seseorang berdasarkan jenis pekerjaan. Jadi jelasnya sasaran pantun kantola bergantung pada identitas, status, karateristik, dan lain-lain seperti yang sudah dijelaskan. Mereka yang terkena sindiran tajam, nada kebencian, dan lainnya yang terungkap dalam kantola, tidak berpengaruh pada hubungan kekeluargaan, kekerabatan, persaudaraan. Kadangkadang merasa tersinggung di saat kantola berlangsung, tetap rasa dendam kesumat tidak bersemi dihati para peserta. Rasa itu setelah kelompok peserta kantola bubar. Mereka pulang ke rumah masing-masing dengan sebuah kenangan indah, bukan kenangan buruk. Itulah kekhasan kantola di kabupaten Muna Laode Padui,( 2011S).

\section{Syair - Syair dalam Kabhanti kantola}

Berikut ini disajikan beberapa syair Kabhanti kantola kaitannya pendidikan karakter yang dapat diintegrasikan dalam pembelajaran Seni Budaya lokal di sekolah menengah kabupaten Muna.

Teks1 (pembuka) (Laki-laki/perempuan) Ombadjangkoalomamomaideruntuteghoomu,daeru ntutesookawudaefehulai,

sookawudaempehulaidamatengkawumpaemo,daer untutetamaakabhedaemalenda.

Sikatumpuunolalokudopoghawatora,dapowawagh ofekirisokaetahaanonamisi, palendatapalendamosumanompalendangkesa

Artinya:

Badan sudah bertabur embun, marilah kita bernyanyi, bernyanyi untuk dikenang, Untuk diingat, jika kita meninggal tidak akan kita berkumpul dan bernyanyi lagi Kita mengalunkan syair sambil dengan sair-sair khiasan Terimakasih kita berjumpa lagi Mari bertukar pikiran untuk ketentraman batin Berkiaslah asalkan yang kiasannya yang baik/membangun). 
Teks 2 (Perempuan)

Amoratoda kaasindo anahiku, atumunggu djunia

ini aelatengkamoisamu.

Saratono katooku arumunsamu lambuku

Derita kabawu lalo sohaenoku lahae

Wa Isina ngkoemu lambuku nontabeae

Amerullah sumintano nohojae asantaamu masamu

nondai lesaku

Dokoambamo dua amerullah noangka hae nosinta

be sintu ini

Kanandohano nosinta amerullah be inodi rohi

atabaindomu

Tapokawu nokoamba kaasi adesantaamu maitu

Nsoono solalono tonobala melangkemu ingka

inodimu ini nthigho fotanggo-tanggono, ingka

inodimu pobelu beluno ini ntigho lumamalamako

Masano nogaatimu lambu nobandibandingi

kanaumu

Tamaka pada runsamo asumabara noafa amala

ntimetahaano, sokaawu kafekiriku asumakundo

djunia

Artinya:

Badan sudah bertabur embun, marilah kita bernyanyi, bernyanyi untuk dikenang,

Untuk diingat, jika kita meninggal tidak akan kita berkumpul dan bernyanyi lagi

Kita mengalunkan syair sambil dengan sair-sair khiasan

Terimakasih kita berjumpa lagi Mari bertukar pikiran untuk ketentraman batin

Berkiaslah asalkan yang kiasannya yang baik/membangun).

Teks 2 (Perempuan)

Amoratoda kaasindo anahiku, atumunggu djunia

ini aelatengkamoisamu.

Saratono katooku arumunsamu lambuku

Derita kabawu lalo sohaenoku lahae

Wa Isina ngkoemu lambuku nontabeae

Amerullah sumintano nohojae asantaamu masamu nondai lesaku

Dokoambamo dua amerullah noangka hae nosinta be sintu ini

Kanandohano nosinta amerullah be inodi rohi atabaindomu

Tapokawu nokoamba kaasi adesantaamu maitu

Nsoono solalono tonobala melangkemu ingka

inodimu ini nthigho fotanggo-tanggono, ingka

inodimu pobelu beluno ini ntigho lumamalamako

Masano nogaatimu lambu nobandibandingi kanaumu

Tamaka pada runsamo asumabara noafa amala

ntimetahaano, sokaawu kafekiriku asumakundo

djunia

Artinya:

Saya ingin ingatkan duhai anak-anaku, saya hidup didunia ini sendiri saat ini

Ketika ajal menjemput, maka rumahku akan kutinggalkan

La Derita sombong hati untuk apalah kupikirkan

Wa isina jangan pula rumahnya dijauhinya

La Merullah yang betah denganku dibujuk oleh La santaamu, katanya bagaimana dia bisa betah tinggal denganku, sedangkan aku pengotor (rumah tidak bersih)

Tapi La santaamu hanya pandai bicara, mungkin dia pikir dia tiba-tiba besar tinggi seperti itu, padahal aku inilah yang menghidupimu, yang merawatmu waktu kecil mungkin karena dia sudah punya rumah sendiri, dia mulai membanding-mabndingkan aku, tetapi biarlah, saya bersabar saja saya mengambil positifnya, untuk saya ingat-ingat ketika saya akan meninggal dunia.

Teks 3 (Laki-laki)

Dentahamadi tingke-tingke suaraku aebanti bantiangko

Fekiri lagi ndosintu tono lengkomo luuku kakodo-

hono mbuuno taranggawu-gawu. Narumato

katooku nekawasa ompu, nolapa omoragho

Kaleramu be indodi tolu gholeo setaghu,

Idi kabaruku dua lagi atanampe angko ne karondo kamentae

Kaasi anaku maitu koe neghawa balaa

Gara isintu omolimpu kanaumu solalomu amatemu kodoghooku mina okobirita ampa tolutaghumu ini, HP nodjala koso bela nokae pulsano

Artinya:

Adentahamadi (nama orang) dengar-dengarkanlah suaraku,

saya akan menyanyi untukmu

Mengingatmu membuat air mataku jatuh, jauhnya kau berada, jika ajalku tiba tidak bisa engkau melihatku,

Ketulusanmu padaku hanya tiga hari dalam setahun Saya sudah cukup gembira, saya mendoakan siang dan malam semoga dijauhkan dari mara bahaya

Padahal kamu sudah lupakan saya

mungkin kamu pikir saya sudah mati 
Karena kamu sudah tidak punya berita lagi sampai tiga tahun ini,

HP jalan terus tapi tak punya pulsa.

Teks 4 (Perempuan)

Wa delabua nolimpu kanau tora,

Solalondo amatemo gara nando kanau alentu-lentu daoa

Aepakatu kaondo be kagantano lobhano

Artinya:

Wadelabua (nama orang) sadah melupakan saya lagi

Mungkin dia pikir saya sudah mati, tapi tidak, saya masih menghitung-hitung waktu pasar, saya akan mengirim ikan kering.

Teks 5 (Laki-laki)

Aitumaka bhelahi palino potaroini, saratono tikarano amoleramo bandara

idi atumanggo paru dopasa nemata satu

nodoli sekorangkuha nofokantibha mbutono,

naekaburino tiga dopobay bayara kupa pada pada

kupa,

tali bhesuku bhaindo obajhinga dotikae nofotika

kaotalohano

lagi nimente-menteghooku agho-ghondo bandara

kolau mpedaahae

ane pomata ngkodoho kobhangu doleloemo,

worahano doalambatuluemo tadombatu-

mbatulumo taka nofoeredamo.

Artinya:

Sungguh mengherankan, jalan-jalannya orang yang berjudi,

kapan sudah tiba waktunya direlakannya bandar,

dan saya yang akan menanggung pikulannya.

Dipasang di mata satu, berbalik sebentar sudah berbunyi kembali,

membenarkan dirinya dikartu yang bertuliskan tiga

Saling berbayar, uang dengan uang, sampai dihabis-

kan.

Berandalan dikelabui dan ditipu sehingga kalah melulu

Yang mengherankan hatiku,

jika saya mengamati bandar sepertinya ada sesuatu, jika tak bermata jeli, semuanya sudah dihabiskan, tampaknya sudah diperas habis-habisan, diperas habis, sampai mereka pulang.
Teks 6 (perempuan)

Kawura-wuragha nale nongkarana haenono

Dongkarana kamomono, bakeno sangkarumara

Nokoambamu wa odje ane okaranga mbadja unsamu unsamu potaro

Artinya:

Cabang kecil yang lemah itu apanya yang dipetik

Memetik pucuknya, buahnya masih hijau

Berbicaralah wa Odhe bahwa kalau kurus badan sudah-sudahlah jangan main judi lagi.

Teks 7 (laki-laki)

Sapae koihi bungke rumato sumuliangko

Matoko wendo inamu ampe wepolangku idi amealaimo

Artinya:

jika rumah kosong aku, aku akan mengembalikanmu ke rumah orangtuamu

Saya hanya akan mengantarmu sampai dididepan pintu/ditangga.

Teks 8 (Perempuan)

Pedamu dua inodi sapae kosoriano lole wutoku tebamba ghoro wutoku welo hola, Nolapasiana folum dua nompoowa rewu

Artinya:

Sama juga denganku jika makanan (mata pencaharian) tidak ada

Sama saja aku menggelindingkan diriku di pinggir tebing batu, dan membuang diriku di dlam jurang bersama dengan sampah lainnya.

Teks 9 (perempuan)

Idiaamenteanemopaleleampaaitu,doteimukalabiad olilidomparaasoampahiseTongkoe, katahoaegholikaialusumaitu, pakaawudafaane tentara pada negholikalupinorombenga,

aitudadihanomoaesowo-sowokundoampakotano-

Kandari, anekotanoKandarikoemudonsarunaane,

latenopandehaanediuwadiumalenodopogholido-

poasodofewuntaghobarandobeLadjabarumaitu.

Artinya:

Sungguh mengherankan perempuan zaman sekarang, kelakuan sudah berlebihan Menjual diri sampai di pasar Tongkoea (kampung), awalnya saya ingin membeli kain, tetapi bagaimana si tentara sudah membeli duluanmendapatkan pakaian 
rombeng, sehingga saya mundur sedikit demi sedikit sampai di kota Kendari. Kalo kota kendari jangan kau harap, semua orang tahu bagaimana pergaulan di sana, berjual beli barang (kelamin) dengan Lajabaru (nama laki-laki).

Teks 10 (Laki-laki)

Ndohodobhongka-

bhongkaraewiteseomemorangku, hamaimindalonod okatambo-tamborie, dofetambokapulundobhahinokominawite, Kilahakumpaaininosidamodogaluewitenompokaapamo, aitumakabhelahikatumbalenongkomena, katatanologhanonosipasamokonahabhekabholunomedawa.

Artinya:

Baru saja tanah (hutan dirambah) untuk perkebunan, siapa saja yang mau, datang membabatkan sedikit-demi sedikit, Menguji peralatannya (parang) apakah tanah itu masih subur. Di saat tanah itu sudah siap olah, betapa herannya, betapa lembeknya ketika ditugal, diliputi oleh sulur-sulur ubi jalar yang sepertinya sudah pernah digali isinya.

\section{Makna dan Nilai-Nilai dalam Teks Kabhanti kantola}

1. Makna Kebersamaan

Makna kebersamaan muncul di awal syair (teks 1) sebagai pembuka. Penekanan pada kebersamaan ini penting karena dalam syair-yair pantun Kabhanti kantola sering mengandung kritikan tajam yang bisa saja melukai hati seseorang atau sekelompok orang, sehingga prinsip-prinsip kebersamaan harus ditegaskan dibagian awal syair kabhanti sebagai pengikat tingkah laku selama berlangsungnya acara tersebut. Jika dimaknai lebih jauh, makna kebersamaan sesungguhnya sebagai respon terhadap pergeseran-pergeseran sosial yang terjadi dalam masyarakat Muna dewasa ini. Paham individualis yang menguat sering dikontraskan dengan lunturnya kebersamaan. Individualisme berarti karakter individu atau tindakan yang merdeka, bebas atau mandiri, sebagai lawan dari kerjasama atau kolektif. Individualisme adalah penekanan pada kemampuan diri sendiri di atas kelompok atau negara (Adi, 2008, hal. 169), bertolak belakang dengan faham kebersamaan dalam prinsip indonesia dan pokadulu dalam prinsip orang Muna.

\section{Bakti kepada Orang Tua}

Teks 2 mencerminkan sikap etika anak terhadap orang tua. Dari teks ini kita dapat mencermati dua hal mengenai kritik yang diberikan kepada anakanak yang melupakan orang tua setelah dewasa. Bagaimana pun orang tua merupakan sosok yang telah melahirkan dan mengantarkan anak-anak kepada kesuksesan. Kewajiban anak menyantuni dan merawat orang tua di masa tua adalah mutlak. Di sisi lain, teks di atas juga memberikan sudut pandang baru bagi orang tua agar selalu berpikir positif mengenai anak-anaknya. Oleh sebab itu, teks Kabhanti kantola ini mengandung himbauan agar anak-anak di kala dewasa tidak melupakan orang tua, dan orang tua pun harus bijak menyikapi kondisi anaknya $\mathrm{Hal}$ ini dipertegas oleh Teks 3, dan 4, mengenai kewajiban anak terhadap orang tua, terutama jika anak tersebut telah menjadi orang sukses.

\section{Larangan Judi}

Teks 5 dan 6 berisi larangan mendekati Judi. Judi dipandang sebagai penyakit yang dapat mematikan perkembangan ekonomi keluarga. Ungkapan ane okaranga mbadja unsamu unsamu potaro mengandung makna bahwa jika kamu belum mapan, maka berhentilah bermain judi. Judi memang menjadi penyakit utama menjangkiti jiwa sebagaian orang yang menjadi candu dalam kehidupan masyarakat. pada teks 5 menegaskan bahaya judi tidak saja membawa kerugian materi tetapi juga memunculkan prilaku-prilaku yang tidak dibenarkan, seperti penipuan selama permainan.

4. Pentingnya Kemapanan Ekonomi dalam Rumah Tangga

Teks 7 dan 8 berisi himbauan untuk mempersiapkan ekonomi secara mapan sebelum memasuki dunia pewakinan bagi pasangan muda mudi. hal ini menjadi penting dan menjadi pemikiran dasar ketika seseorang memutuskan untuk menikah. Jika dulu laki-laki tidak menuntut wanita harus bekerja sebagai istrinya, sekarang pandangan itu berubah. Lakilaki juga memikirkan pentingnya istri bekerja, bukan sebagai membantu penghasilan suami tetapi untuk sama-sama menompang kehidupan berumah tangga. Di situ dikatakan baik laki-laki dan perempuan harus memiliki bekal (koihi bungke, kasoria) sebelum memasuki dunia rumahtangga. Perempuan mengatakan bahwa jika laki-laki tidak memiliki kasoria (susunan jagung) dalam hal ini sumber mata pencaharian maka sama saja ia membuang dirinya dalam jurang. Artinya bahwa ia tidak akan 
mengambil resiko ketika menikahi laki-laki yang tidak memiliki sumber penghasilan. Begitu juga dengan laki-laki ia mengatakan bahwa sapaa koihi bungke (jika tidak ada isinya peti) simpanan, dalam artian bekal, tidak akan mengambil resiko menikahi wanita yang tidak memiliki bekal (potensi) apapun yang dapat dikembangkan menjadi sumber penghasilan. Kalimat ini dapat dimaknai sebagai pentingnya kemapanan ekonomi untuk masa depan.

\section{Etika dalam Pergaulan}

Teks 9 dan teks 10 merupakan kritik terhadap prilaku pemuda dan pemudi dalam pergaulan masa kini. Masalah prostitusi adalah bukan masalah baru dalam kehidupan umat manusia dan tetap menjadi sorotan tajam di kalangan masyarakat. Bobroknya moral manusia akan berdampak bobroknya segala sendi kehidupan manusia, dalam konteks Muna, moral menjadi kata kunci dalam perjalanan manusia menuju manusia yang dirahmati oleh Allah SWT. Simbol kota kendari dalam kutipan di atas bukan menunjuk kota Kendari yang dalam realitas adalah ibu kota Sulawesi Tenggara, tetapi kota Kendari merupakan simbol kehidupan kota besar dan prilaku masyarakatnya. Di samping itu, perempuanlah yang paling dirugikan dalam rusaknya pergaulan itu. Teks 10 mengindikasikan dampak yang terjadia pada wanita ke depannya jika ia sudah bobrok dalam pergaulan. Meskipun kedua gender ini sama-sama berpotensi untuk terlibat dalam pergaulan bebas, namun perempuanlah yang paling banyak merasakan dampak buruknya, terutama kaitanya dengan masa depannya. Dengan demikian keberadaan teks ini merupakan kritik tentang prilaku menyimpang dalam segi asusila dalam masyarakat, dan menjadi bahan pemikiran bagi generasi muda.

Pembahasan kali ini dibatasi pada pengungkapan 10 teks kabanti kantola dan 5 makna dan nilai. Meskipun demikian masih banyak nilai-nilai yang berkaitan dengan pendidikan karakter yang dapat diintegrasikan dalam kutikulum lokal pembelajaran Seni Budaya pada sekolah menengah di Kabupaten Muna. pengintegrasian ini selain memperkuat kurikulum pendidikan karakter yang sudah dicanangkan oleh pemerintah secara nasional, cara ini juga dapat melestarikan tradisi lokal yang hampir punah.

\section{SIMPULAN}

Berdasarkan uraian di atas, tulisan ini menyimpulkan bahwa pendidikan karakter terintegrasi dalam pendidikan seni budaya yang berbasis budaya lokal sangat penting diterapkan di sekolah-sekolah khususnya di Kabupaten Muna. Makna dan nilai yang muncul dalam teks-teks Kabhanti kantola mengandung berbagai ajaran, nasehat, dan kritikkritik yang membangun, membimbing, dan mengarahkan karakter masyarakat pendukungnya, untuk menjadi baik dan positif berdasarkan sudut pandang (pandangan dunia) masyarakatnya. Nilai-niali itu diantaranya adalah menumbuhkan rasa kebersamaan, ajaran mengenai etika dalam pergaulan, bakti kepada orang tua, pentingnya kemapanan ekonomi sebelum berkeluarga, dan larangan terhadap judi. Kritik, arahan, dan pesan seperti ini dimaksudkan untuk menciptakan keseraian, keselarasan, dan keseimbangan sosial dalam kehidupan bermasyarakat, serta mempertahankan nilai-nilai moralitas yang diyakini benar oleh masyarakat Muna dan dapat terus diinternalisasi oleh generasi muda sepanjang masa.

\section{DAFTAR RUJUKAN}

Ader Laepe, Rohmana.(2006) Analisis Semiotik Atas Lirik Kantola. Kantor Bahasa Provinsi Sulawesi Tenggara, Kendari.

Adi, R,A. (2008), Mitos di Balik Film Laga Amerika. Gadah Mada University Press, Yogyakarta.

Bardia, La Ode.(2006)Wacana Kantola di Kabupaten Muna dalam Perspektif Linguistik Kebudayaan. Universitas Udayana, Denpasar.

Bernard,S, \&Girouard J. (1992) "Colinda: MysteriousOrigins of a CajunFolksong", dalam Journal of Folklore Research, 29(1): 37-52. Indiana University Press

Blum, S. (1974). "Persian Folksong in Meshhed (Iran), 1969". dalam Yearbook of the International Folk Music Council, Vol. 6: 86-114

Conway, C. (2003). "Black Banjo Songsters in Appalachia". Black Music Research Journal, Vol. 23, No. 1/2 (Spring - Autumn, 2003), pp. 149-166 
Darius L. Thieme. (1960) "Negro Folksong Scholarshipinthe United States". dalam African Music, 2(3) : 67-72

Fatimah Abdullah, (2009). "Pantun sebagai Perakam Norma Terhadap Perkawinan dan Keluarga Melayu”, dalam Jurnal Melayu (4), 2009 : 43 $-57$

Hashim, HJ. M, Normahdiah, S. S. Rozita, C.R. Siti Sarah. A. K, ( 2012). "Hati Budi Melayu: Kajian Kepribadian Melayu kearah Penjanaan Melayu Gemilang", dalam Journal of Language Studies, Volume 12 (1) 2012.

La Niampe. (1998). Kabhanti Bula Malino: Kajian Filologis Sastra Wolio Klasik. Tesis Universitas Padjajaran, Bandung.

La Mokui. (1991). Kabhanti Wuna. CV Astri Raha, Raha.

Novita Wulasari, Hasnul F. Syafiani, ( 2013). "Nilai nilai Pendidikan Karakter dalam Pantun Minangkabau", dalam Jurnal, Volume 1 No. 6.

Padui, La Ode. (2011), Makna dan Nilai Kantola pada Masyarakat Muna. Penelitian di Kabupaten Muna, Propinsi Sulawesi Tenggara. Universitas Haluoleo, Kendari.

La Ode Sidu, Usman Rianse, La Ode Padui, (2011). "Kantola in the Context of Muna Culture", dalam Mudra, 26(3): 268-278.

Reichenbach, H. (1983) "The Tonality of English and Gaelic Folksong", dalam Music\&Letters, 19(3): 268-279

Sari, D. (2011), Revitalisasi Tradisi Lisan Kantola Masyarakat Muna Sulawesi Tenggara pada Era Globalisasi. Universitas Indonesia, Jakarta.

Sitti, Abadi, (2012). Analisis Wacana Kabhanti kantola Wuna. Universitas Haluoleo, Kendari. 